\title{
Biopsychosocial Factors Associated with Active or Sedentary Lifestyles of Children and Adolescents in Costa Rica
}

\author{
Hilda Núñez-Rivas' ${ }^{1}$, Ileana Holst-Schumacher ${ }^{2 *}$, Sonia Guzmán-Padilla1, Marlen Rosello-Araya ${ }^{1}$, \\ Natalia Campos-Saborío ${ }^{3}$ \\ ${ }^{1}$ Institute for Research and Education on Nutrition and Health (INCIENSA), Tres Ríos, Costa Rica \\ ${ }^{2}$ Faculty of Microbiology, University of Costa Rica and Research Center in Hematology and Related Disorders, San José, Costa Rica \\ ${ }^{3}$ Distance State University, San José, Costa Rica \\ Email: hnunez@inciensa.sa.cr, ‘ileana.holst@ucr.ac.cr, sguzman@inciensa.sa.cr,mrosello@inciensa.sa.cr, \\ natalia.campos0745@gmail.com
}

How to cite this paper: Núñez-Rivas, H., Holst-Schumacher, I., Guzmán-Padilla, S., Rosello-Araya, M., \& Campos-Saborío, N. (2020). Biopsychosocial Factors Associated with Active or Sedentary Lifestyles of Children and Adolescents in Costa Rica. Advances in Physical Education, 10, 476-491. https://doi.org/10.4236/ape.2020.104037

Received: September 20, 2020 Accepted: November 23, 2020

Published: November 26, 2020

Copyright (c) 2020 by author(s) and Scientific Research Publishing Inc. This work is licensed under the Creative Commons Attribution-NonCommercial International License (CC BY-NC 4.0). http://creativecommons.org/licenses/by-nc/4.0/ (c) (i) (s) Open Access

\begin{abstract}
Background: Sedentary lifestyle in children and adolescents has been associated in multiple investigations with lack of healthy recreation, low academic performance and socialization, drug use and a higher rate of violence. On the other hand, physical activity has been considered a protective factor for the prevention of non-communicable diseases and health promotion. Objective: To determine the association between sedentary or active behaviors and biopsychosocial factors of children and adolescents of Costa Rica. Materials and Methods: Descriptive cross-sectional study in a population of 2284 students from 64 educational centers (40 elementary schools and 24 high schools) in Costa Rica in 2016. A total of 1063 elementary students were interviewed and 1221 middle and high school students completed a validated and self-administered questionnaire under the supervision of the researchers. Information was collected on sociodemographic, anthropometric data, dietary, psychosocial factors and on sedentary behavior. Logistic regression models were performed to examine the association between biopsychosocial factors and sedentary or active lifestyles in children. Results: The study points out that more than half of the children and adolescents (52.0\%) are sedentary and $64.0 \%$ do not follow the recommendations for the use of screen time. Only $44.0 \%$ are active and follow the screen time recommended. The characteristics of the children and adolescents who are sedentary and spend too much screen time are related to younger age, male sex, high socioeconomic status, and belong to an extended family structure $(p<0.05)$. Conclusions: According to the multivariate models tested, the biopsychosocial variables
\end{abstract}


statistically associated with sedentary lifestyles were age, being female, school violence, not having parental support, living in unsafe spaces and without recreational areas, belonging to the "Emo" subculture, not having a healthy diet, belonging to an extended family and quantity of relatives who are not used to do physical activity. This evidence should be considered for the design of comprehensive interventions that seek to reverse sedentary behaviors in children and adolescents.

\section{Keywords}

Physical Activity, Sedentary Lifestyle, Psychosocial Factors, Children and Adolescents, Costa Rica

\section{Introduction}

According to the World Health Organization (WHO), sedentary lifestyle in children and adolescents is associated with lack of healthy recreation, low academic performance and socialization, drug use, as well as a higher rate of violence among other aspects. One of the strategies to face these problems that affect society today is physical activity, which is one of the protective factors for the prevention of non-communicable diseases and health promotion. In young people aged 5 to 17 years, the WHO recommends that they dedicate a minimum of 60 minutes a day to physical activities of moderate to vigorous intensity, at least three times a week (WHO, 2020). Costa Rica, like some Western countries, has high indices of overweight and obesity in school and adolescent population, which has been increasing over the years as shown by the different surveys and studies carried out (Encuesta Nacional de Nutrición 2008-2009, 2013; Núñez et al., 2003, Censo Escolar de Peso y Talla, 2016).

The High School Survey of Nutritional Surveillance and Physical Activity carried out in Costa Rica in 2018 to 8297 students between the ages of 13 and 17 from public and private schools in urban and rural areas; found that $31 \%$ of adolescents had excess body weight (21.2\% with overweight and $9.8 \%$ with obesity). Also, they reported that unhealthy food consumption habits persist, as well as little physical activity (Ministerio de Salud, 2018).

Another study based on a sample of 1.6 million students between the ages of 11 and 17 from 146 countries, carried out by WHO from 2001-2016, indicates that global trends in physical activity of teenagers are insufficient. Consequently, there is a clear need for urgent action to increase levels of physical activity among girls and boys aged 11 to 17 years. It is estimated that more than $80 \%$ of adolescents ( $85 \%$ girls and $78 \%$ boys) do not perform the minimum recommended level of one hour of physical activity per day (Guthold et al., 2020).

Physical inactivity is defined as a level of activity that is insufficient to meet the recommendations, a minimum of 60 minutes a day in moderate to vigorous intensity physical activities, at least three times/week. In children and young 
people, sedentary behavior is often referred to as the equivalent of participating in 2 hours or more a day, in recreational activities that consist of screen time that is not related to school or college tasks or work, such as, watching television, using a smartphone/tablet, using a computer to play games, or simply chatting through social media (Tremblay et al., 2017).

The different conceptualizations of physical inactivity, sedentary behavior and its associated adverse health outcomes have become an area of growing interest in recent years. Studies indicate that the combination of "active + non-sedentary" is the optimal one to achieve health benefits, while the combination of "inactive + sedentary" is associated with the highest risk of adverse health outcomes (Saunders et al., 2016).

In this study, the participating population of elementary-middle schools and high schools, from the seven provinces of Costa Rica, was classified into these two categories, in order to examine the possible association between biopsychosocial factors and sedentary/active behaviors of children and teenagers. The results of this study may be useful to recommend the implementation of a comprehensive-holistic intervention that promotes changes in lifestyles in sedentary children and adolescents.

\section{Materials and Methods}

\subsection{Type of Study and Selection of the Population}

A descriptive cross-sectional study was carried out in a population of 2284 students (from the fourth grade of elementary school to the fifth year of high school) from 64 educational centers (40 elementary-middle schools and 24 high schools) in Costa Rica in 2016. The sample size was calculated using the proportional estimation formula, with a confidence level of $95 \%$ and an error range of $3 \%$. In each educational center approximately 36 children or adolescents were randomly selected. Exclusion criteria included: incomplete participant information and inability to read and write.

\subsection{Data Collection}

A total of 1063 elementary school students were interviewed and 1221 high school students were administered a validated and self-administered questionnaire. The questionnaire was subject to numerous expert reviews and validated with a pilot test in children and adolescents. Students were explained how to complete the questionnaire, subsequently, they responded individually in each of their classrooms, accompanied by two researchers, who answered doubts, if necessary. An average of 25 minutes was required to complete the questionnaire.

\subsection{Study Variables}

\subsubsection{Sociodemographic and Family Characteristics}

Data on sex, nationality, age, education and socioeconomic level and other as- 
pects of the families were collected. Socioeconomic level was determined according to the methodology described by Madrigal (1997) that considers the possession of specific material goods in the home. Family structure (nuclear, matrifocal or extended), family coexistence and the physical activity performed by parents or guardians were also investigated. Likewise, parental support was measured, for which an index was constructed with five questions $(1=$ No, $0=$ Yes) and a scale was developed where if the sum was $\leq 3$ points, it means that the child or adolescent having parental support and $>3$ points means they do not have parental support.

\subsubsection{Anthropometric Data}

Weight was determined to all students using a Tanita scale model SC-331 S (without column) and height was determined using a freely positioning stadiometer with a wall separator, SECA brand, model 217. Body weight was measured with the subject barefoot and in light clothing (shorts and T-shirt). Height was measured in an upright position, back to the measuring rod with the internal malleoli together and heels, buttocks, shoulders and posterior region of the head in contact with the apparatus. Waist circumference (WC) was measured at the mid-point between the lowest rib and the top of the iliac crest on naked skin at the end of a normal expiration. Waist-to-height ratio was calculated as WC (in centimeters) divided by height (in centimeters). Two measures were performed twice for each child and teenager and the averages of them were calculated. A third measurement was performed if a difference greater than $0.5 \mathrm{~cm}$ was noticed between the two measurements. Abdominal obesity was defined using the waist-height cut-off point of 0.50 (Browning, Hsieh, \& Ashwell, 2010) and the waist circumference cut adopted by Taylor et al (2000). All measurements were performed by trained health care workers using standardized techniques. Body mass index (BMI) was calculated $\left(\mathrm{kg} / \mathrm{m}^{2}\right)$ and based on the WHO recommendations were classified as: underweight: $\mathrm{SD} \leq-2$, normal: $-2<\mathrm{SD} \leq$ 1, overweight: $1<\mathrm{SD} \leq 2$, obese: $\mathrm{SD}>2$ (de Onis, Onyango, \& Borghi, 2009). Overweight and obesity were defined according to the WHO Child Growth Standards Length/height for age, weight for age, weight for length, weight for height and BMI for age.

\subsubsection{Lifestyles Information}

Through a validated questionnaire, students were asked to report on the intake frequency of food and with this information the participants' diet was analyzed using a new index, built to evaluate the quality of the diet and classify it as healthy or unhealthy (Núñez, Holst, \& Campos, 2020). Dichotomous questions (yes, no) about the use of licit and illicit drugs were also considered.

\subsubsection{Psychosocial Data}

Dichotomous questions (yes, no) about school violence (bullying), belonging to urban groups and environmental infrastructure were considered. 


\subsubsection{Sedentary Behavior}

The sum of screen hours ( 0 - 24 hours/day) was made, considering the frequency of four sedentary behaviors during the weekdays and weekends: watch television, play with the computer or console, connect to the Internet and talk to friends on the phone or Skype daily. The cut-off point for total screen time was established at a maximum of 2 hours per day, in accordance with the guidelines of the American Academy of Pediatrics (American Academy of Pediatrics, 2001) and the guidance provided by Tremblay et al. (Tremblay et al., 2017).

In addition, questions about the weekly frequency of physical activity outside the educational centers (never, 1 - 2 - 3 - 4 - 5 - 6 times a week and daily, on average $\geq 60$ minutes/day) (U.S. Department of Health and Human Services, 2008), on the practice of physical activity in the educational center were included. With this information, those participants who fulfilled two conditions were recoded as active: the sum of hours of screen ( $0-24$ hours/day) when it was less than 2 hours a day and the weekly frequency of physical activity outside the educational center in average $\geq 60$ minutes/day, was more than three days a week. The rest of the participants who did not meet these two conditions were recoded as sedentary.

\subsection{General and Ethical Procedures}

Participants gave their informed consent or written assent to be included in the study. These documents were approved by the Scientific Ethics Committees of the institutions involved in the study and all the procedures carried out complied with the ethical standards.

\subsection{Statistical Analysis}

Descriptive statistics using averages, standard deviations and frequencies (percentages) were used to summarize the sociodemographic, family, anthropometric, dietary and psychosocial characteristics, as well as the use of legal and illegal substances, according to their absolute and relative distribution in the behaviors categories. The prevalence of each of the behaviors categories (active or sedentary) was estimated.

The chi square test $\left(\mathrm{X}^{2}\right)$ was used to evaluate the importance of the differences between the categorical variables, adopting a critical value of $p<0.05$. Differences between groups are explained by parametric or non-parametric tests according to the normal distribution. Data defined by more than two categories were tested using ANOVA, Mann-Whitney or Kruskal-Wallis tests, depending on the distribution.

Finally, logistic regression models were performed to examine the possible association between sedentary or active behaviors and biological, psychosocial, sociodemographic, dietary and environmental infrastructure factors, where children and adolescents develop. The adjusted odds ratios (OR) and their 95\% confidence intervals (CI) and etiological or preventive fractions, as the case may be, are presented. Table 1 shows the explanatory variables included in the tested 
Table 1. Variables included in the tested and fitted models.

\begin{tabular}{|c|c|}
\hline Variables & Categorization \\
\hline- Sex & Male $=0$, Female $=1$ \\
\hline - Age in completed years & continuous variable \\
\hline - Socioeconomic index & $\begin{array}{c}\text { continuous and } \\
\text { dichotomous variable: } \\
\text { (low, middle and } \\
\text { high level) }\end{array}$ \\
\hline - Types of family structure (nuclear, matrifocal and extended) & Yes $=1$, No $=0$ \\
\hline - Number of family members who are used to do physical activity & continuous variable \\
\hline - Your neighborhood has spaces for recreation and physical activity & No $=1$, Yes $=0$ \\
\hline - Your community is safe & $\mathrm{No}=1, \mathrm{Yes}=0$ \\
\hline - Your diet is not healthy & $\mathrm{Yes}=1, \mathrm{No}=0$ \\
\hline - Body Mass Index & continuous variable \\
\hline $\begin{array}{l}\text { - With risk of cardiovascular disease according to the } \\
\text { waist/height ration indicator }\end{array}$ & Yes $=1$, No $=0$ \\
\hline - You have felt rejection in your educational center. & Yes $=1$, No $=0$ \\
\hline - You have parental support & No $=1$, Yes $=0$ \\
\hline - Student physically assaults you & Yes $=1$, No $=0$ \\
\hline - Student teases you & Yes $=1$, No $=0$ \\
\hline - Number of licit and illicit drugs (consumption) & continuous variable \\
\hline $\begin{array}{l}\text { - You are part of the following groups: Emo, Metalhead, } \\
\text { Rocker, Skate, Phosphorescent, Hiphopper or Gothic }\end{array}$ & Yes $=1$, No $=0$ \\
\hline
\end{tabular}

Source: own elaboration of the authors.

and adjusted models. All the analysis was carried out with the SPSS version 24.0 program.

\section{Results}

A total of 2284 students participated in this study. The $52.6 \%$ of the participants were female and the average age was $13.06 \pm 2.05$ years. The $56 \%(\mathrm{n}=1278)$ of the students were classified as sedentary, being women more sedentary compared to men $(55.9 \%$ vs $44.1 \%, p<0.018)$. The average age of the sedentary population was $13.17 \pm 2.10$ years, significantly older than the average age of the active population $(12.93 \pm 1.97$ years, $p=0.017)$. Only $13 \%$ of the students were physically active seven days a week, $14 \%$ six days, $10 \%$ five days, $11 \%$ four days, and $52 \%$ three days or less. In relation to screen time, $36 \%$ of students spend less than 2 hours per day, $29 \%$ between 2 and 4 hours per day and 35\% for more than 4 hours per day. Other biopsychosocial characteristics of the studied population are presented in Table 2.

The students who accomplished with physical activity and the screen time recommendations were the youngest $(p<0.001)$, male $(p<0.018)$, from high 
Table 2. Characteristics of active and sedentary students of elementary, middle and high schools in Costa Rica, 2016.

\begin{tabular}{|c|c|c|c|c|c|c|c|c|}
\hline & \multirow{2}{*}{ Variables } & \multicolumn{2}{|c|}{$\begin{array}{c}\text { Active } \\
(\mathrm{n}=1006)\end{array}$} & \multicolumn{2}{|c|}{$\begin{array}{c}\text { Sedentary } \\
(\mathrm{n}=1278))\end{array}$} & \multicolumn{2}{|c|}{$\begin{array}{c}\text { Total } \\
(\mathrm{n}=2284)\end{array}$} & \multirow{2}{*}{$p$} \\
\hline & & $\mathrm{n}$ & $\%$ & $\mathrm{n}$ & $\%$ & $\mathrm{n}$ & $\%$ & \\
\hline & & 518 & 51.5 & 563 & 44.1 & 1081 & 47.4 & 0.018 \\
\hline & & 488 & 48.5 & 715 & 55.9 & 1203 & 52.6 & 0.014 \\
\hline & & 12.93 & $=1.97$ & 13.17 & \pm 2.10 & $13.06=$ & +2.05 & $0.017^{\mathrm{a}}$ \\
\hline \multicolumn{9}{|c|}{ Family Structure } \\
\hline & & 801 & 79.6 & 955 & 74.7 & 1756 & 76.9 & 0.018 \\
\hline & 1 support & 988 & 98.2 & 1216 & 95.2 & 2204 & 96.5 & 0.001 \\
\hline
\end{tabular}

\section{Environmental infrastructure}

- Recreation in the neighborhood

$\begin{array}{rccccccc}\text { Yes } & 703 & 69.9 & 204 & 15.9 & 907 & 39.7 & 0.001 \\ \text { No } & 303 & 30.1 & 1074 & 84.1 & 1377 & 60.3 & 0.001 \\ \text { - Unsafe Neighborhood } & 875 & 87.0 & 1252 & 98.0 & 2127 & 93.1 & 0.001\end{array}$

\section{Lifestyle}

- Overweight/obese)

\section{No \\ Yes}

- Cardiovascular risk

\begin{tabular}{|c|c|c|c|c|c|c|c|}
\hline Without & 707 & 70.3 & 835 & 65.4 & 1542 & 67.5 & 0.046 \\
\hline With & 299 & 29.7 & 443 & 34.6 & 742 & 32.5 & 0.188 \\
\hline - Unhealthy diet & 892 & 88.7 & 1169 & 91.5 & 2061 & 90.2 & 0.040 \\
\hline - Has used less than 3 legal and illegal drugs & 983 & 97.7 & 1208 & 94.5 & 2191 & 95.9 & 0.001 \\
\hline - Has used more than 3 legal or illegal drugs & 23 & 2.3 & 70 & 5.5 & 93 & 4.1 & 0.055 \\
\hline - He doesn't snort cocaine & 996 & 99.0 & 1249 & 97.7 & 2245 & 98.3 & 0.029 \\
\hline \multicolumn{8}{|l|}{ Psychosocial variables } \\
\hline - They have not mocked & 784 & 77.9 & 897 & 70.2 & 1681 & 73.6 & 0.001 \\
\hline - They have mocked & 222 & 22.1 & 381 & 29.8 & 603 & 26.4 & 0.050 \\
\hline - Is not rejected & 925 & 91.9 & 1060 & 83.0 & 1985 & 86.9 & 0.001 \\
\hline - They have not hit him/her & 755 & 75.0 & 868 & 67.9 & 1623 & 71.1 & 0.002 \\
\hline \multicolumn{8}{|l|}{ Urban group } \\
\hline Gothic & 53 & 5.3 & 96 & 7.5 & 149 & 6.5 & 0.864 \\
\hline Hiphopper & 83 & 8.2 & 45 & 3.5 & 128 & 5.6 & 0.514 \\
\hline Emos & 100 & 9.9 & 176 & 13.8 & 276 & 12.1 & 0.450 \\
\hline Metalheads & 112 & 11.1 & 194 & 15.2 & 306 & 13.4 & 0.405 \\
\hline Skater & 273 & 27.1 & 95 & 7.4 & 368 & 16.1 & $<0.001$ \\
\hline Phosphorescent & 185 & 18.4 & 70 & 5.5 & 255 & 11.2 & 0.017 \\
\hline Does not belong to any subculture & 200 & 19.9 & 602 & 47.1 & 802 & 3.4 & $<0.001$ \\
\hline
\end{tabular}

$\begin{array}{lllllll}758 & 75.3 & 933 & 73.0 & 1691 & 74.0 & 0.309\end{array}$

$\begin{array}{lllllll}248 & 24.7 & 345 & 27.0 & 593 & 26.0 & 0.593\end{array}$

$\begin{array}{lllllll}53 & 5.3 & 96 & 7.5 & 149 & 6.5 & 0.864\end{array}$

$\begin{array}{lllllll}100 & 9.9 & 176 & 13.8 & 276 & 12.1 & 0.450\end{array}$

$\begin{array}{lllllll}112 & 11.1 & 194 & 15.2 & 306 & 13.4 & 0.405\end{array}$

$\begin{array}{lllllll}273 & 27.1 & 95 & 7.4 & 368 & 16.1<0.001\end{array}$

$\begin{array}{lllllll}185 & 18.4 & 70 & 5.5 & 255 & 11.2 & 0.017\end{array}$

$\begin{array}{lllllll}200 & 19.9 & 602 & 47.1 & 802 & 3.4 & <0.001\end{array}$
${ }^{a}$ Mann-Whitney U test. 
socioeconomic status $(p<0.001)$ and belonged to a non-matrifocal family ( $p<$ 0.018). The proportions of active young people compared to sedentary ones were significantly higher with respect to having parental support $(p<0.001)$ and with a higher number of family members who used to perform physical activity $(p<$ 0.001 ), they lived in neighborhoods with areas to do recreation/physical activity $(p<0.001)$, while a higher number of sedentary youths compared to active ones reported that their communities were unsafe due to crime or delinquency ( $p<$ 0.001), not suitable for physical activity outdoors.

The number of active young people compared to sedentary ones was significantly lower in relation to smoking, inhalation of cement, cocaine and the amount of added addictions $(p<0.001)$. A higher proportion of the active participants in contrast to the sedentary ones reported not having experienced rejection $(p<0.001)$ or "bullying" or some type of physical $(p<0.002)$ and psychological $(p<0.001)$ violence. The number of active young people without cardiovascular risk was significantly higher than that of sedentary ones $(p<0.046)$. Likewise, a higher proportion of sedentary kids had an unhealthy diet $(p<$ 0.040).

According to the bivariate analysis, in terms of belonging to urban groups, more active young people were Hiphoppers, Phosphorescents and Skaters $(p<$ 0.001 ) and more sedentary young people were part of the groups called Emos ( $p$ $=0.450)$, Metalheads $(p=0.405)$ and Gothics $(p=0.864)$.

Table 2 shows the results of the logistic regression analysis. After adjusting for covariates to examine the sedentary behavior in children and young people, the variables that were not statistically associated were: socioeconomic status, body mass index, belonging to a matriarchal, nuclear or nuclear with a stepfather or stepmother family and belonging to a subculture such as Hiphoppers, Phosphorescents, Metalheads, Rockers and Gothics $(p<0.050)$.

The biopsychosocial variables statistically associated with sedentary lifestyle are presented in Table 3 (in descending order according to the odds ratio and etiological or preventive fraction), being the main aggressor factors those of a psychosocial type, such as, feeling rejected (OR $=5.28,95 \%$ IC $3.19-7.76)$; not having parental support ( $\mathrm{OR}=2.11,95 \%$ IC 1.49 - 2.73); being physically assaulted $(\mathrm{OR}=2.02,95 \%$ IC $1.49-2.73)$ and mocked by peers $(\mathrm{OR}=1.49,95 \%$ IC 1.10 - 1.90). Also, being part of the Emo group (OR $=2.32$, 95\% IC 1.49 3.63) and some factors related to environmental infrastructure and lifestyle, turned out to be aggressors; among these: living in communities or neighborhoods without spaces for recreation ( $\mathrm{OR}=5.21,95 \%$ IC $3.54-7.42)$ and unsafe $(\mathrm{OR}=3.14,95 \%$ IC $1.60-5.69)$ and not having a healthy diet $(\mathrm{OR}=1.74,95 \%$ IC 1.19 - 2.53). Being part of the Skater subculture turned out to be a preventative factor $(\mathrm{OR}=0.13,95 \%$ IC $0.10-0.17)$; as well as having an extended family structure $(\mathrm{OR}=0.43,95 \%$ IC $0.27-0.69)$, whose members have the habit of doing some kind of physical activity $(\mathrm{OR}=0.51,95 \%$ IC $0.41-0.65)$.

The goodness-of-fit of this multivariate model of biopsychosocial variables associated with the sedentary behavior of the children and adolescents in the 
Table 3. Multivariate model of biopsychosocial variables statistically associated with sedentary behavior.

\begin{tabular}{|c|c|c|c|c|c|c|c|c|}
\hline \multirow[t]{2}{*}{ Variables } & \multirow[t]{2}{*}{$\beta$} & \multirow[t]{2}{*}{ OR } & \multicolumn{2}{|c|}{$\begin{array}{l}95 \% \text { C.I. } \\
\text { for } \operatorname{EXP}(B)\end{array}$} & \multirow{2}{*}{$\begin{array}{l}\text { Standard } \\
\text { Error }\end{array}$} & \multirow[t]{2}{*}{$P$} & \multirow{2}{*}{$\begin{array}{c}\begin{array}{c}\text { Etiological } \\
\text { fraction }\end{array} \\
\text { Exposed }\end{array}$} & \multirow{2}{*}{$\begin{array}{l}\text { Preventive } \\
\text { fraction } \\
\text { ases (\%) }\end{array}$} \\
\hline & & & Lower & Superior & & & & \\
\hline \multicolumn{9}{|l|}{ 1. Psychosocial variables } \\
\hline $\begin{array}{l}\text { You have felt that you are rejected in your } \\
\text { educational center }(\text { Yes }=1, \mathrm{No}=0)\end{array}$ & 1.665 & 5.285 & 3.190 & 7.769 & 0.207 & $<0.001$ & 81.1 & - \\
\hline Has parental support $(\mathrm{No}=1, \mathrm{Yes}=0)$ & 1.337 & 3.807 & 2.110 & 7.560 & 0.368 & $<0.001$ & 73.7 & - \\
\hline Student physically assaults you $(\mathrm{Yes}=1, \mathrm{No}=0)$ & 0.704 & 2.022 & 1.493 & 2.738 & 0.155 & $<0.001$ & 50.5 & - \\
\hline Student teases you $($ Yes $=1$, No $=0)$ & 0.385 & 1.496 & 1.107 & 1.904 & 0.153 & 0.017 & 33.2 & - \\
\hline \multicolumn{9}{|l|}{ 2. Environmental infrastructure } \\
\hline $\begin{array}{l}\text { Your neighborhood has spaces for recreation and } \\
\text { physical activity }(\text { No }=1 \text {, Yes }=0)\end{array}$ & 1.652 & 5.217 & 3.549 & 7.422 & 0.193 & $<0.001$ & 80.8 & - \\
\hline Your community is safe $(\mathrm{No}=1$, Yes $=0)$ & 1.147 & 3.148 & 1.606 & 5.694 & 0.359 & 0.001 & 68.2 & - \\
\hline \multicolumn{9}{|l|}{ 3. Belonging to an urban group } \\
\hline Emo $($ Yes $=1$, No $=0)$ & 0.840 & 2.328 & 1.490 & 3.636 & 0.227 & $<0.001$ & 57.0 & - \\
\hline Skater $($ Yes $=1$, No $=0)$ & 2.017 & 0.133 & 0.109 & 0.179 & 0.180 & $<0.001$ & - & 86.7 \\
\hline \multicolumn{9}{|l|}{ 4. Lifestyle } \\
\hline Your diet is not healthy & 0.554 & 1.741 & 1.193 & 2.539 & 0.193 & 0.004 & 42.6 & - \\
\hline Number of vices (continuous variable, 0 - 5) & 0.475 & 1.419 & 1.100 & 1.867 & 0.120 & $<0.001$ & 29.5 & - \\
\hline \multicolumn{9}{|l|}{ 5. Biological variables } \\
\hline Gender $(1=\mathrm{F}, 0=\mathrm{M})$ & 0.475 & 1.609 & 1.267 & 2.043 & 0.122 & $<0.001$ & 37.8 & - \\
\hline Age in completed years (continuous variable) & 0.099 & 1.104 & 1.029 & 1.173 & 0.030 & 0.007 & 9.4 & - \\
\hline \multicolumn{9}{|l|}{ 6. Family variables } \\
\hline Your family is of type extended $($ Yes $=1, \mathrm{No}=0)$ & 0.825 & 0.438 & 0.277 & 0.694 & 0.234 & $<0.001$ & - & 56.5 \\
\hline $\begin{array}{l}\text { Number of family members who usually } \\
\text { do physical activity (continuous variable) }\end{array}$ & 0.658 & 0.518 & 0.412 & 0.651 & 0.117 & $<0.001$ & - & 48.2 \\
\hline
\end{tabular}

$\alpha=-5.167$, represents the value of the intercept of the equation of the straight line, when the independent variables take zero value.

study is significant (chi-square significance of the model in the omnibus test $<$ 0.05). This model explains between 0.436 ( $R^{2}$ of Cox and Snell's) and $0.587\left(R^{2}\right.$ of Negelkerke's) the part of the variance of the dependent variable (sedentary lifestyle) and correctly predicts $82.9 \%$ of sedentary lifestyle cases. In addition, the $p$ value associated with the Hosmer-Lemeshow test in this model is higher than 0.05 , which means that the model fits reality and is well explained with the variables included. Therefore, this model is acceptable.

\section{Discussion}

In this study, more than half of the children and adolescents (52.0\%) are not active and $64.0 \%$ do not follow the recommendations for the use of the screen time. In fact, only $44.0 \%$ meet both conditions. The characteristics of the child- 
ren and adolescents who made both recommendations are related to younger age, male sex, high socioeconomic status and belong to a type of extended family structure.

The prevalence of screen time of the students of this research is similar to the one reported by other studies, where they indicate that the use of television or the computer reached $63 \%$ among youngsters, the use of video games was higher among boys and mobile phones/tablets among girls (Delfino et al., 2018). Another study realized in Finland reports that out of a total of 486 participants (238 girls, 248 boys), $66 \%$ of the girls and $54 \%$ of the boys performed less than two hours of total physical activity per day $(p=0.012)$. This outcome match with the results of the present study, where girls had higher levels of total sedentary lifestyle ( 3.8 vs. $3.4 \mathrm{~h} /$ day, $p=0.015)$ than boys. However, their levels per screen time ( 1.5 vs. $1.9 \mathrm{~h} /$ day, $p<0.001)$ were lower than the boys (Lampinen et al., 2017).

Regarding the socioeconomic status, in the Finnish study it was found that the levels of parental education and low family income were related to higher levels of sedentary lifestyle in boys (time dedicated in front of the screen) but not in girls $(p=0.005$ and $p<0.001$, respectively). These levels were associated with low supervised physical activity in both genders (Lampinen et al., 2017). The present study found, through bivariate analysis, that a higher number of active children and adolescents were of high socioeconomic status compared to the sedentary ones. Also, it is evidenced that a higher proportion of sedentary young people compared to active young people had an unhealthy diet. It is confirmed that active boys who were not at risk of cardiovascular disease (according to the waist-height ratio indicator) were significantly higher than sedentary boys, which could be based on the association reported by other studies, where the high use of screen devices is associated with a high intake of sandwiches, fried foods, sweets and physical inactivity in adolescents (Delfino et al., 2018). These results are characteristic of Western countries, where a large proportion of children and adolescents do not meet recommended physical activity guidelines and those who are more physically active generally have lower levels of body fat than those who are less active (Hills, Andersen, \& Byrne, 2011).

However, it is interesting that the accomplishment of both recommendations examined in this study (frequency of physical activity-60 minutes a day, 4 or more days a week-and less than two hours of screen time a day) was not enough to have lower probabilities of being overweight/obese (excess weight), since it is considered that the diet and not so much the physical activity of children and adolescents, could be playing a preponderant role in the generation of excess body weight. In addition, it should be considered that the BMI only measures excess body weight in relation to height, not body fat, which is not evenly distributed in the body. The BMI is unable to predict and detect cardiovascular disease, while WC is a measure of central adiposity (Suder, Gomula, \& Koziel, 2017; Ford, Mokdad, \& Giles, 2003; Vásquez et al., 2007; Güngör, 2014).

Hence the importance of the waist/height indicator, which in this study al- 
lowed us to have another complementary dimension of the analysis to detect that a higher number of active children and adolescents did not present cardiovascular risk compared to sedentary ones.

On the other hand, the environmental infrastructure aspects and most of the psychosocial factors examined in this study were more favorable for active children and adolescents than for sedentary ones. According to the multivariate analysis and the etiological fractions, $80.8 \%$ and $68.2 \%$ respectively of the cases of sedentary lifestyle could be attributable to the place where children and adolescents live. That means in neighborhoods that do not have spaces for recreation and physical activity and communities that are not safe (delinquency and criminality). These results support the theory that green spaces are an important environmental influence on physical activity and emotional well-being of children and young people (Ward et al., 2016).

Likewise, the exposures suffered by children and adolescents to rejection, physical violence and psychological bullying (mocking) by their peers. According to the multivariate analysis carried out in the present study, they were strongly associated with sedentary lifestyle (the odds ratios range between 2 and 5.3). The etiological fractions of $81.1 \%, 50.5 \%$ and $33.2 \%$ respectively of the cases of sedentary lifestyle could be attributable to these aggressive psychosocial factors. A study that included 6269 Danish students aged 11, 13 and 15, reported that exposure to bullying was associated with physical inactivity $(\mathrm{OR}=2.39,1.67$ - 3.41) and that there is a higher probability of physical inactivity among students from the lowest social classes and for those exposed to bullying. These results and those of the present study, give rise to the hypothesis that there could be a combined effect of low social class, bullying and physical inactivity (Henriksen et al., 2016).

On the other hand, for the prevention of relationship problems among schoolchildren that lead to bullying situations, healthy lifestyle habits and sports practice (not competitive) should be considered because they promote responsibility and improve coexistence. In fact, the results of a study of 1248 high school students between the ages of 11 and 18 indicate that students who practiced competitive physical activity had higher values in aggressiveness indicators than students who presented a lower physical activity frequency, being this behavior more common among boys than girls (Méndez, Ruiz, \& Ortega, 2019).

In this study, it was evidenced that parental support and the homes where the majority of family members perform physical activity are factors that favor children and adolescents to be active. These results could explain the protective effect of belonging to an extended family, that is, a large family (with first, second and even third consanguinity) and that a significant number of its members are used to do physical activity. In fact, if these two conditions were present among children and adolescents, a sedentary lifestyle could be avoided in 56.5\% and $48.2 \%$ of exposed cases, respectively. An obesogenic home environment is known to be an important factor in overeating and promoting a sedentary lifestyle in school-age children, since they have less autonomy during this phase of 
development and are influenced by family environmental signals.

Hence the need for this contemporary society to become aware of the influence of parents and family members as role models for children and adolescents to adopt healthy lifestyles behaviors (Herbenick et al., 2018). A Canadian study confirms the positive influence that physical activity modeling and parental support have on the child's physical activity level, whether both conditions are fulfilled or only one of the two (Garriguet, Colley, \& Bushnik, 2017). According to the multivariate analysis and the preventive fractions to explain sedentary behavior, in our study the presence of parental support in children and adolescents could prevent a sedentary lifestyle in $73.7 \%$ of exposed cases.

It is known that levels of physical activity decrease during adolescence as age increases (Damjanovic et al., 2019). This fact is consistent with what was found in this study, where age ( $\mathrm{OR}=1.104,1.029-1.173)$ is an aggressive factor associated with sedentary lifestyle, as well as the number of drugs (continuous variable) consumed by children and adolescents in Costa Rica ( $\mathrm{OR}=1.419,1.100$ 1.867). In this regard, a longitudinal study with adolescents from Bosnia and Herzegovina (Damjanovic et al., 2019), reported that the relationship between the consumption of illicit drugs and the decrease in physical activity could be the result of a large number of children who stop practicing competitive sports in this period of life. In addition, this longitudinal study concludes that to achieve appropriate levels of physical activity, special attention should be paid to children whose mothers are not highly educated, who live in rural communities and who report substance abuse (cigarette, alcohol, and illicit drug use).

In relation to be part of a youth subculture or so-called urban tribe, the present study is considered to be a pioneer in examining, through multivariate analysis, its association with the sedentary behavior of children and adolescents. The literature indicates that it is expected that a person chooses to be part of a subculture, during their late childhood or adolescence. By definition, a subculture is a group within a larger culture that differs because it possesses its own belief system, values and practices. Subcultures often help adolescents to develop their own individual identity (Slee, 2011). In our study, belonging to the "Emo" subculture was associated with sedentary lifestyle (odds ratio 2.3 , 95\% CI 1.5 3.6), the etiological fraction being 57\%; which means that the cases of sedentary lifestyle could be attributable to this aggressive factor and the explanation for this behavior can be attributed to the fact that young people spend up to half their time in leisure activities, whether structured or not (Graham, 2010).

Added to this, the "Emos" in general, are really thin young people and are characterized for being shy and calm, they are not muscular or "very masculine" men and they seem to have less interest in the values of patriarchal culture, masculine traditional activities and in sports that "are for men." They also represent a rebellion against the rigid gender roles imposed on them by the patriarchal social system, where tight clothing is for girls and sports for boys, reason why masculine men label them as "queers". However, the "Emos" fit well in 
a show and are seen as cute or normal, while in the school environment they can be labeled as "queer or different" and be the joke for their peers (Schmitt, 2011).

This "Emo" subculture is opposed to the "Skatos" subculture, since the former carry out leisure activities, listen to diverse and varied musical sub-genders of rock, punk, hardcore punk, they display their costumes, accessories and do not require physical exercise, which is expected among inactive children and young people with sedentary behaviors (Schmitt, 2011).

Belonging to the subculture called "Skatos" turned out to be a protective factor of sedentary lifestyle, in $87 \%$ of exposed cases. This finding could be explained in the freedom to move around in various settings, which is a basic attraction of "skateboarding" for children and adolescents, in contrast to traditional sports, where obligatory practices are generally carried out and rules must be followed. The act of skating has no rules and the user is free to skate in the way they like best and without the adults exercising their control and impositions towards the decision to enjoy free time and use the available spaces, which are frequently taken by adults (Slee, 2011).

According to the study of Graham (2010), several positive learning opportunities are linked to the use of skate parks, where skaters experience a sensation of accomplishment, identity and camaraderie with their peers. Contrary to the notion that only structured and supervised adult entertainment yields favorable developmental outcomes, this research found links between the 'unstructured' activities that occur within skate parks, such as opportunities for focus and homework challenge, meaningful identity development and broader social integration.

\section{Strengths and Limitations of the Study}

The sample of this study is large, probabilistic and representative at the level of elementary, middle and high schools in Costa Rica. Also, all measures were validated and carried out by highly trained and standardized personnel. Confidentiality was guaranteed to participating children and teenagers and validated and anonymous instruments were used. Although, the design of this study is cross-sectional, so it allows only inferences about associations and not about causes. The sociodemographic data and family characteristics were based on self-records, which may be influenced by social convenience and memory bias.

\section{Conclusion}

The results of this study may be useful to achieve the implementation of comprehensive-holistic interventions that promote changes in the lifestyles of children and adolescents, emphasizing age (late adolescence and girls), prevention and control of school violence, the support and modeling of family members, urban planning with safe spaces and areas for recreation and the promotion of membership to various healthy subcultures that routinely practice companionship, solidarity, respect, scrolling motion and physical activity. 


\section{Conflicts of Interest}

The authors declare no conflicts of interest regarding the publication of this paper.

\section{References}

American Academy of Pediatrics (2001). Children, Adolescents, and Television. Pediatrics, 107, 423-426. https://doi.org/10.1542/peds.107.2.423

Browning, L., Hsieh, S., \& Ashwell, M. A. (2010). Systematic Review of Waist-to-Height Ratio as a Screening Tool for the Prediction of Cardiovascular Disease and Diabetes: 0.5 Could Be a Suitable Global Boundary Value. Nutrition Research Reviews, 23, 247-269. https://doi.org/10.1017/S0954422410000144

Censo Escolar de Peso y Talla [Internet] (2016). https://www.mep.go.cr/sites/default/files/page/adjuntos/informe-ejecutivo-censo-escol ar-peso-cortofinal.pdf

Costa Rica: Encuesta Nacional de Nutrición 2008-2009. Nodo Costa Rica-Campus Virtual de Salud Pública [Internet] (2013).

https://costarica.campusvirtualsp.org/costa-rica-encuesta-nacional-de-nutricion-20082009

Damjanovic, V. M., Salcin, L. O., Zenic, N., Foretic, N., \& Liposek, S. (2019). Identifying Predictors of Changes in Physical Activity Level in Adolescence: A Prospective Analysis in Bosnia and Herzegovina. International Journal of Environmental Research and Public Health, 16, 2573. https://doi.org/10.3390/ijerph16142573

de Onis, M., Onyango, A., \& Borghi, E. (2009). WHO Child Growth Standards. Length/Height-for-Age, Weight-for-Age, Weight-for-Length, Weight-for-Height and Body Mass Index for Age. Methods and Development. World Health Organization. http://www.who.int/childgrowth/standards/Technical_report.pdf?ua=1

Delfino, L., Dos Santos, S. D., Tebar, W., Zanuto, E., Codogno, J., Fernández, R., \& Christofaro, D. (2018). Screen Time by Different Devices in Adolescents: Association with Physical Inactivity Domains and Eating Habits. The Journal of Sports Medicine and Physical Fitness, 58, 318-325.

Ford, E. S., Mokdad, A. H., \& Giles, W. H. (2003). Trends in Waist Circumference among U.S. Adults. Obesity Research, 11, 1223-1231. https://doi.org/10.1038/oby.2003.168

Garriguet, D., Colley, R., \& Bushnik, T. (2017). Parent-Child Association in Physical Activity and Sedentary Behaviour. Health Reports, 28, 3-11.

Graham, L. B. (2010). Skate Parks as a Context for Adolescent Development. Journal of Adolescent Research, 25, 288-323. https://doi.org/10.1177/0743558409357236

Güngör, N. K. (2014). Overweight and Obesity in Children and Adolescents. Journal of Clinical Research in Pediatric Endocrinology, 6, 129-143.

https://doi.org/10.4274/jcrpe.1471

Guthold, R., Stevens, G., Riley, L., \& Bull, F. (2020). Global Trends in Insufficient Physical Activity among Adolescents: A Pooled Analysis of 298 Population-Based Surveys with 1.6 Million Participants. Revista: The Lancet Child \& Adolescent Health, 4, 23-35. https://doi.org/10.1016/S2352-4642(19)30323-2

Henriksen, P. W., Rayce, S. B., Melkevik, O., Due, P., \& Holstein, B. E. (2016). Social Background, Bullying, and Physical Inactivity: National Study of 11- to 15-Year-Olds. Scandinavian Journal of Medicine \& Science in Sports, 26, 1249-1255.

https://doi.org/10.1111/sms.12574 
Herbenick, S., James, K., Milton, J., \& Cannon, D. (2018). Effects of Family Nutrition and Physical Activity Screening for Obesity Risk in School-Age Children. Journal for Specialists in Pediatric Nursing, 4, e12229. https://doi.org/10.1111/jspn.12229

Hills, A. P., Andersen, L. B., \& Byrne, N. M. (2011). Physical Activity and Obesity in Children. British Journal of Sports Medicine, 45, 866-870.

https://doi.org/10.1136/bjsports-2011-090199

Lampinen, E. K., Eloranta, A. M., Haapala, E. A., Lindi, V., Väistö, J., Lintu, N., Karjalainen, P., Kukkonen, K., Laaksonen, D., \& Lakka, T. A. (2017). Physical Activity, Sedentary Behaviour, and Socioeconomic Status among Finnish Girls and Boys Aged 6-8 Years. European Journal of Sport Science, 17, 462-472. https://doi.org/10.1080/17461391.2017.1294619

Madrigal, J. (1997). La construcción de índices. San José: Editorial Universidad de Costa Rica.

Méndez, I., Ruiz, C., \& Ortega, E. (2019). Impact of the Physical Activity on Bullying. Frontiers in Psychology, 2, 1520. https://doi.org/10.3389/fpsyg.2019.01520

Ministerio de Salud (2018). Encuesta Colegial de Vigilancia nutricional y actividad física en adolescentes de zona rural y urbana.

https://www.ministeriodesalud.go.cr/index.php/centro-de-prensa/noticias/741-noticias $\underline{-2020 / 1537}$

Núñez, H. P., Holst, I., \& Campos, N. (2020). New Diet Quality Index for Children and Adolescents in Costa Rica. Nutricion Hospitalaria, 37, 65-72.

Núñez, H. P., Monge, R., León, H., \& Roselló, M. (2003). Prevalence of Overweight and Obesity among Costa Rican Elementary School Children. Revista Panamericana de Salud Pública, 13, 24-32. https://doi.org/10.1590/S1020-49892003000100004

Organización Mundial de la Salud (WHO) (2020). Estrategia mundial sobre régimen alimentario, actividad física y salud. Sobrepeso y Obesidad Infantiles. http://www.who.int/dietphysicalactivity/childhood/es

Saunders, T. J., Gray, C. E., Poitras, V. J., Chaput, J. P., Janssen, I., \& Katzmarzyk, P. T. (2016). Combinations of Physical Activity, Sedentary Behaviour and Sleep: Relationships with Health Indicators in School-Aged Children and Youth. Applied Physiology Nutrition and Metabolism, 41, S283-S293. https://doi.org/10.1139/apnm-2015-0626

Schmitt, K. (2011). Exploring Dress and Behavior of the Emo Subculture. Dissertations, Theses and Capstone Projects, Paper 465.

https://digitalcommons.kennesaw.edu/cgi/viewcontent.cgi?article=1466\&context=etd

Slee, T. (2011). Skate for Life: An Analysis of the Skateboarding Subculture. Outstanding Honors Theses, Paper 29. http://scholarcommons.usf.edu/honors_et/29

Suder, A., Gomula, A., \& Koziel, S. (2017). Central Overweight and Obesity in Polish Schoolchildren Aged 7-18 Years: Secular Changes of Waist Circumference between 1966 and 2012. European Journal of Pediatrics, 176, 909-916. https://doi.org/10.1007/s00431-017-2938-4

Taylor, R., Jones, I., Williams, S., \& Goulding, A. (2000). Evaluation of Waist Circumference, Waist-to-Hip Ratio, and the Conicity Index as Screening Tools for High Trunk Fat Mass, as Measured by Dual-Energy X-Ray Absorptiometry, in Children Aged 3-19 Year. The American Journal of Clinical Nutrition, 72, 490-495.

https://doi.org/10.1093/ajcn/72.2.490

Tremblay, M. S., Aubert, S., Barnes, J. D., Saunders, T. J., Carson, V., \& Latimer, A. E. (2017). Sedentary Behavior Research Network (SBRN)-Terminology Consensus Project 
Process and Outcome. International Journal of Behavioral Nutrition and Physical Activity, 14, 75. https://doi.org/10.1186/s12966-017-0525-8

U.S. Department of Health and Human Services (2008). Physical Activity Guidelines for Americans and Youth Physical Activity Guidelines Toolkit. Washington DC: Author. http://www.health.gov/PAguidelines/guidelines/chapter3.aspx

Vásquez, G., Duval, S., Jacobs, D. R. et al. (2007). Comparison of Body Mass Index, Waist Circumference, and Waist/Hip Ratio in Predicting Incident Diabetes: A Meta-Analysis. Epidemiologic Reviews, 29, 115-128. https://doi.org/10.1093/epirev/mxm008

Ward, J. S., Duncan, J. S., Jarden, A., \& Stewart, T. (2016). The Impact of Children's Exposure to Greenspace on Physical Activity, Cognitive Development, Emotional Wellbeing, and Ability to Appraise Risk. Health Place, 40, 44-50.

https://doi.org/10.1016/j.healthplace.2016.04.015 